\title{
P77 Long-term Effects of LDL Apheresis on Carotid Arterial Atherosclerosis in Two Severe Heterozygous Familial Hypercholesterolemic Patients
}

\author{
Ágnes Diószegi, Lilla Juhász, Bíborka Nádró, György Paragh, László Oláh, Dénes Páll, \\ József Balla, Mariann Harangi
}

University of Debrecen Faculty of Medicine, Debrecen, Hungary

\begin{abstract}
The long-term effects of low-density lipoprotein (LDL) apheresis (LA) on the progression and regression of atherosclerosis were evaluated by carotid ultrasonography in two severe heterozygous familial hypercholesterolemic patients with carotid artery stenosis. Furthermore, the lipid-lowering efficacy of LA was evaluated. A 63-year-old male and a 64-year-old female patient have been followed for severe heterozygous $\mathrm{FH}$, being treated by LA for 5 years continuously, at 4 -week intervals, added on a standard high-dose statin and ezetimibe therapy. The regular LA treatment significantly decreased the levels of total cholesterol (by -58.1 and $-53.8 \%$ ) and LDL-C (by -69 and $-66 \%$ ), while the HDL-C levels did not change significantly. The time-averaged LDL-C (TAL) levels were also significantly decreased (by 20.8 and $30.1 \%$ ). Still, we could not achieve the $1.8 \mathrm{mmol} / \mathrm{L}$ LDL-C goal values (average TAL levels were 4.1 and $5.1 \mathrm{mmol} / \mathrm{L}$ ). Carotid ultrasonography was performed in every 6 months; internal carotid arteries (ICA) and common carotid arteries (CCA) were evaluated on both sides. Although during the 5-year follow-up we found a progression in the left ICA of the male patient (from 20\% to 45\%), all the other parameters showed the slow up of the atherogenesis in the studied arteries. The results suggest that monthly LA-treatment can significantly delay the progression of the atherosclerotic process in FH patients, however, it is not adequate to stop progression in every case because of TAL levels exceeding the LDL-C goal value. LA treatment twice a month or PCSK9 inhibitor therapy should be considered to further lower LDL-C.
\end{abstract}

(c) 2019 Association for Research into Arterial Structure and Physiology. Publishing services by Atlantis Press International B.V. This is an open access article distributed under the CC BY-NC 4.0 license (http://creativecommons.org/licenses/by-nc/4.0/). 